\title{
Toward a framework for developing an ICF-based documentation system in spinal cord injury-specific rehabilitation based on routine clinical practice: a case study approach
}

\author{
Kannit Pongpipatpaiboon ${ }^{1} \cdot$ Melissa Selb ${ }^{2,3} \cdot$ Apichana Kovindha $^{4} \cdot$ Birgit Prodinger $^{2,3,5}$
}

Received: 8 December 2019 / Revised: 16 April 2020 / Accepted: 17 April 2020

(c) The Author(s), under exclusive licence to International Spinal Cord Society 2020

\begin{abstract}
Study design Case study.

Objective To present a framework for developing an International Classification of Functioning, Disability and Health (ICF)-based documentation system in spinal cord injury (SCI)-specific rehabilitation.

Setting Data collection took place at Maharaj Hospital, Thailand. The preparatory studies and analysis were performed at Swiss Paraplegic Research, Switzerland.

Methods Data collected from interviews and health records of four SCI cases across the continuum of care (acute, postacute, early and late long term) were linked to ICF categories using established ICF linking rules. The resulting categories were compared with selected ICF sets (ICF Generic-30, ICF core sets for SCI and multiple sclerosis) to determine the extent of coverage. Furthermore, the context of applicable services was described systematically.

Results Less than half of the ICF categories in the defined ICF sets were covered by clinical assessment tools. Low correspondence was found predominantly in acute and late long-term phase. Least well covered were categories of activities and participations and environmental factors. The correspondence of categories increased when considering the additional ICF categories identified from patient interviews. The description of rehabilitation services provided in each case classified according to the dimensions of service provider, funding, and service delivery.

Conclusions There is a need to promote the systematic and standardized assessment of functioning among health professionals working in the field of SCI in developing countries. This study describes basic steps toward developing a standardized ICF-based system for assessing and reporting functioning outcomes in SCI rehabilitation and across the continuum of care.
\end{abstract}

Supplementary information The online version of this article (https:// doi.org/10.1038/s41394-020-0283-8) contains supplementary material, which is available to authorized users.

Kannit Pongpipatpaiboon ning665@gmail.com

1 Department of Rehabilitation Medicine, Samitivej Srinakarin Hospital, Bangkok, Thailand

2 Swiss Paraplegic Research, Nottwil, Switzerland

3 ICF Research Branch, Nottwil, Switzerland

4 Department of Rehabilitation Medicine, Faculty of Medicine, Chiang Mai University, Chiang Mai, Thailand

5 Faculty of Applied Health and Social Sciences, Technical University of Applied Sciences Rosenheim, Rosenheim, Germany

\section{Introduction}

Functioning is the primary goal of rehabilitation [1-3]. The World Health Organization (WHO) recognizes functioning as a health status indicator, complementary to morbidity and mortality [4-6]. WHO's International Classification of Functioning, Disability and Health (ICF) provides a standard for describing functioning [7] that reflects the impact of a health condition on a person's lived experience in light of environmental factors [4]. Enhancing health information systems with functioning information has the potential to strengthen rehabilitation and healthcare as a whole. Functioning information also provides a foundation for clinical decision-making in rehabilitation and the allocation of rehabilitation services $[4,5,8]$. Although various clinical assessment tools (CATs), including clinical tests, patientreported outcome measures, clinician-administered 
questionnaires, etc., exist, there is no single standard for which CATs to use to collect functioning information in rehabilitation practice $[9,10]$. Moreover, the heterogeneity in CATs challenges the comparability of information collected. Thus, establishing a standardized database of CATs, using the ICF as a reference, for rehabilitation is warranted. The ICF is the most suitable reference therefore since it is the international standard for describing functioning. Persons with spinal cord injury (SCI) have various functioning limitations and impairments, which influence their activities in daily life [11-13]. Rehabilitation services provided at any point along the continuum of care are an indispensable resource for responding to the needs and challenges experienced by persons with SCI [14, 15]. Rehabilitation is not bound to services provided in rehabilitation facilities but also includes services provided in acute hospitals with the aim of improving functioning.

In Thailand, a high incidence of SCI prevails, particularly among young and middle-aged males. The most common cause of SCI is road traffic accidents [16, 17]. Despite the high incidence rate, there is lack of inpatient rehabilitation services dedicated for persons with SCI. Currently, many SCI patients are discharged home after acute care, placing much of the responsibility for health maintenance in the hands of a family member as a primary caregiver, e.g., by training the family member to continue physical therapy at home. Accessibility to healthcare for persons with SCI in rural areas is especially difficult due to a lack of rehabilitation services and a shortage of rehabilitation professionals, especially in community hospitals [18]. In addition, as in many parts of the world, there is currently no systematic functioning documentation of persons with SCI in Thailand in real-life clinical practice. As a first step toward developing a standardized ICF-based system for documenting functioning of persons with SCI in Thailand, it is important to examine how functioning information is currently being collected in Thailand in and across the different settings along the continuum of care. To ensure that health and rehabilitation services provided at the different stages of care (e.g., acute, post-acute, and long term) are not fragmented but integrated and continuous, it is important to promote the continuity of information exchange next to management continuity and continuity of trusting relationship between patient and health professionals and among health professionals along the care continuum [19]. Therefore, the objective of this study was to present a framework for developing an ICF-based documentation system in SCI-specific rehabilitation across the continuum of care by using a case study approach. More specifically, we aimed (1) to identify the existing CATs used in rehabilitation practice from acute to community care and (2) to determine the extent these tools cover the ICF categories contained in existing ICF sets (i.e., predefined lists of ICF categories reflecting the most relevant domains to be considered in describing functioning in a given population) $[20,21]$. This study was conducted in a collaborative effort between Swiss Paraplegic Research and the Rehabilitation Department, Faculty of Medicine at Chiang Mai University.

\section{Methods}

A descriptive case study design was employed. Case studies allow to describe in-depth and compare how functioning is assessed and documented, if at all, in real-life routine rehabilitation practice [22].

We identified individual patients in each phase in the continuum of care, i.e., acute $(<1$ month), post-acute (1 month to 1 year), early long-term (1-10 years), and late long-term phases ( $>10$ years). Acute phase was defined as the first period after sudden damage or trauma to the spinal cord, which mainly focused on medical and surgical care with limited structured rehabilitation interventions. The post-acute phase begins with active rehabilitation and ends with the completion of the first comprehensive rehabilitation after the onset of SCI. The post-acute phase is then followed by the long-term (or chronic) phase [23-26].

We conducted patient interviews (PIs) to gain an understanding of functioning from the perspective of persons with SCI. Furthermore, we conducted a health records review of the identified patients to identify the CATs used in each case. The PIs and CATs were linked to the ICF and compared with relevant ICF sets. In addition, service provider interviews (SPIs) took place in order to provide a comprehensive picture of the rehabilitation setting corresponding to each case. Since the information collected during the SPIs was mainly about the respective setting and corresponding service provision, data were linked to the first version of the International Classification of Service Organization in Health-related Rehabilitation (ICSO-R) [27]. An overview of the study design is outlined in Fig. 1.

\section{Patient recruitment}

Persons with SCI who received rehabilitation services at Maharaj Nakorn Chiang Mai Hospital, a tertiary care facility in Northern Thailand, were recruited. The Rehabilitation Department of Maharaj Nakorn Chiang Mai Hospital has led the efforts to use the ICF in clinical practice in Thailand. Patient recruitment was based on the principle of maximum variation considering the criteria shown in Table 1. Using these criteria, the chief nurse of the rehabilitation ward identified patients as potential participants.

After receiving approval from the local principle investigator, the nurse provided the patients with general study 
Fig. 1 Methodology of data collection and analysis. ICF International Classification of Functioning, Disability and Health, ICSO-R International Classification of Service

Organization in Health-related Rehabilitation, SCI spinal cord injury.

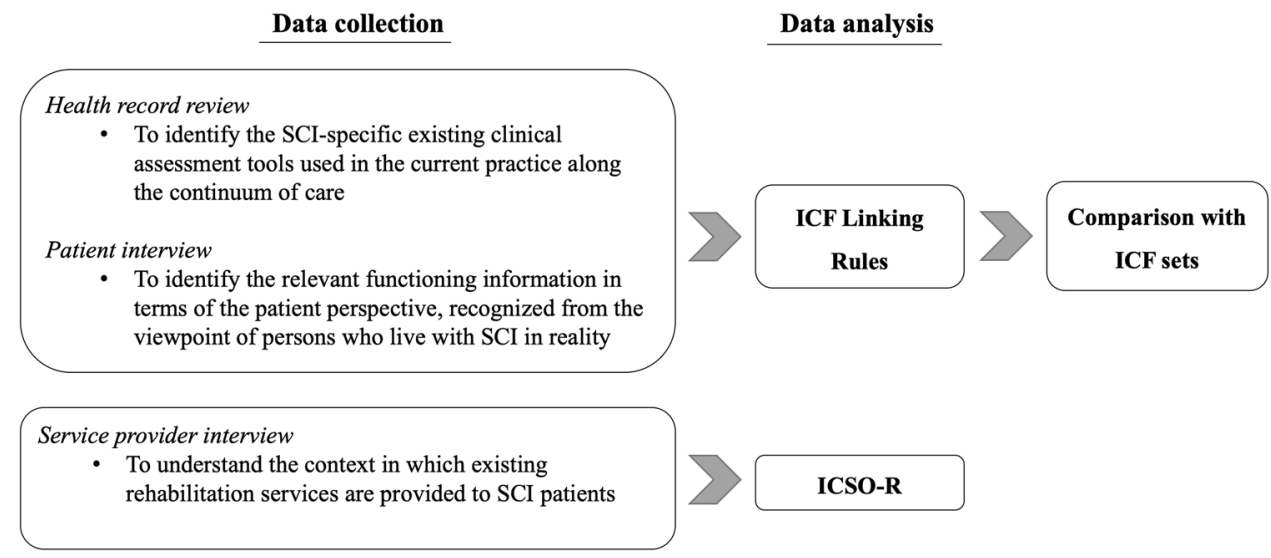

Table 1 In- and exclusion criteria.

Inclusion criteria:

Adults $\geq 18$ years old

Men and women

Persons with SCI with lesions at four levels (cervical, thoracic, lumbar, sacral) and severity based on American Spinal Injury Association ASIA (A, B, C, D)

Persons with traumatic or nontraumatic SCI

Persons with varying durations of time since injury, including acute $0-1$ month, post-acute 1 month to 1 year, early long term $1-10$ years, late long term $>10$ years

Persons treated in different rehabilitation services across the continuum of care

Exclusion criteria:

Persons with impaired cognitive function and an inability to communicate in an interview

information and invited them to participate. The principal investigator provided the patients who agreed to participate in the study detailed information about the purposes of the study and acquired the patients' informed consent.

\section{Data collection methods}

Data were obtained from PIs, health record review, and SPIs. In the case of SCI patients whose time since injury fell within the early long-term or late long-term phase, the health records of their last hospitalizations were also reviewed.

\section{Patient interview (PI)}

The semi-structured PIs were conducted in Thai by the first author using an ICF-based interview guide developed for this study. The interviewer posed seven open-ended questions addressing the ICF components of body functions, activities and participation, and environmental factors (Appendix 1). All interviews were tape-recorded and transcribed in verbatim.

\section{Health record review}

The patients' health records were reviewed for relevant information including current medical status, disease characteristics, length of hospital stay, and the CATs that were employed to evaluate people's functioning. Relevant information also included the time points when various CATs were administered and by whom. Also recorded was whether tools were employed more than once.

\section{Service provider interview}

To get a comprehensive understanding about the context of the respective rehabilitation services, the service providers responsible for the provision of the rehabilitation treatment of each patient were interviewed. To describe the rehabilitation services systematically, ICSO-R informed the interview guide and served as the foundation for analyzing the data. An overview of the dimensions and corresponding categories of ICSO-R is provided in Table 2.

\section{Data analysis}

\section{Linking data to ICF}

To determine the extent to which the results of the PIs and health record review cover the content contained in existing ICF sets, the established process of linking health and healthrelated information to the ICF was applied [28]. ICF sets contain a selection of ICF categories most important for a given group of persons, e.g. persons with stroke, or in a given setting, e.g. post-acute or long-term rehabilitation settings. The selection was performed based on a multi-stage approach in which existing evidence and international expert opinion was considered. Thus, the existing ICF sets relevant for a given area of practice can be seen as an internationally agreed upon reference of what domains of functioning should be considered in a given group of persons or in a given setting. Two researchers familiar with the ICF conducted the linking 
Table 2 Dimensions and selected categories of the International Classification of Service Organization in Health-related Rehabilitation (ICSO-R)

\section{Service provider}

Location, organization, context, facility, human resources, technical resources, quality assurance, profit orientation, and other categories of provider

\section{Funding}

Sources of money, criteria of cost refund, and other criteria of funding

Service delivery

Strategy, target groups, service goals, aspects of time, intensity, team structure, mode of production, and other categories of service delivery

Service provider: location (centralized vs. decentralized service, situated in rural area vs. urban area, accessibility, and other dimensions of location); organization (independent organization, affiliation, or other dimensions of organization); context (single practice, community-based service, institutional care, such as nursing home or hospital-based service, home based); facility (building, hotel service, and other aspects of facility); human resources (health professionals, administrative staff, technical staff, and other personnel); technical resources and equipment (diagnostic devices, therapeutic devices and treatment modalities, data procession and communication, and other technical resources); quality assurance (total quality assurance system, single quality assurance measures, and other methods of quality assurance); profit orientation (profit-oriented, non-profit organization as charity organization and others, and other aspects of profit orientation). Funding: source of money (health insurances, pension insurances, accident insurance or other insurances, social welfare system, private payment, e.g. out-of-pocket payment, founds, or other sources of money); criteria of cost refund (diagnosis-related group system, day-based payment, or other systems). Service delivery: strategy (preventive strategy, curative strategy, rehabilitation strategy, maintenance/supportive strategy, or other health strategies); target groups (patients with defined health conditions, persons with specific deficits in body functions, activities and participation, etc.); service goals (improvement of health status, improvement of self-care, return to normal life, return to work, or other service goals); aspects of time (phase of disease, time-frame of intervention, number and duration of treatment time per day, and other aspects of time); intensity (high, medium or low intensity or other dimensions of intensity); team structure (involved professions, team organization, e.g., multidisciplinary team, interdisciplinary team); mode of production (hospitalization, inpatient service, day clinic, outpatient service, or other modes of production).

of the PI and health record review results to the ICF. The first step in the linking process was conducted by the first author that involved identifying meaningful concepts based on the data from the health record review and PI. For example, for "patient could not walk as expected", the meaningful concept was "walking". The list of concepts was then linked to the most relevant ICF categories by two researchers independently using the latest version of the established ICF Linking Rules (Fig. 2) [28]. The two researchers compared their individual results and came to an agreement. In case of disagreement, a third researcher was consulted. The same linking procedure was employed to identify the ICF categories covered by the CATs used in assessing the patient. The linking results are presented at the second level of the ICF hierarchy in this study.

\section{Data comparison with ICF sets}

To determine to what extent the participants' functioning is represented in ICF sets, a mapping comparison was performed. This involved comparing the ICF categories from the linking of the health record review and PIs with the categories of relevant ICF sets, and identifying the extent of overlap using descriptive statistics. Regarding the selection of ICF sets, the ICF Generic-30 Set (ICF G-30) [20] was selected as the base ICF set for every case study, since the ICF G-30 categories are considered the most essential categories relevant for documenting functioning of persons with various health conditions. As shown in Table 6, the Brief ICF Core Set for SCI for post-acute settings [23] and for long-term settings [29] were selected in alignment with the context of each case. These core sets were selected as their corresponding categories have been identified as the most essential for capturing the functioning of persons with SCI through an established scientific consensus process $[23,29]$. An overview of the selected ICF sets across the continuum of care as a standardized reference of functioning is shown in Fig. 3.

Likewise, the linking results of the CATs were compared with the linking results of the patient's functioning (PI and health records review) as well as the ICF sets to determine the extent the CATs identified in each case cover the categories in the ICF sets and those specific to the individual participant. Descriptive statistics, i.e. frequency analysis, were performed.

\section{Service provision classification}

Rehabilitation services provided in the case studies across the continuum of care were described using the ICSO-R [27].

\section{Results}

Out of five SCI patients who met the inclusion criteria and were invited to participate in the study, four agreed to participate. One person declined participation. At the time of the PIs, the patients in cases 1,2 , and 3 were engaged in rehabilitation during their inpatient stay in the orthopedic and rehabilitation ward. Case 4 took place at an outpatient neurological clinic. The demographic data and characteristics of the participants are shown in Table 3 . 
Fig. 2 Linking process based on the ICF Linking Rules [22]. ICF International Classification of Functioning, Disability and Health, QOL quality of life.

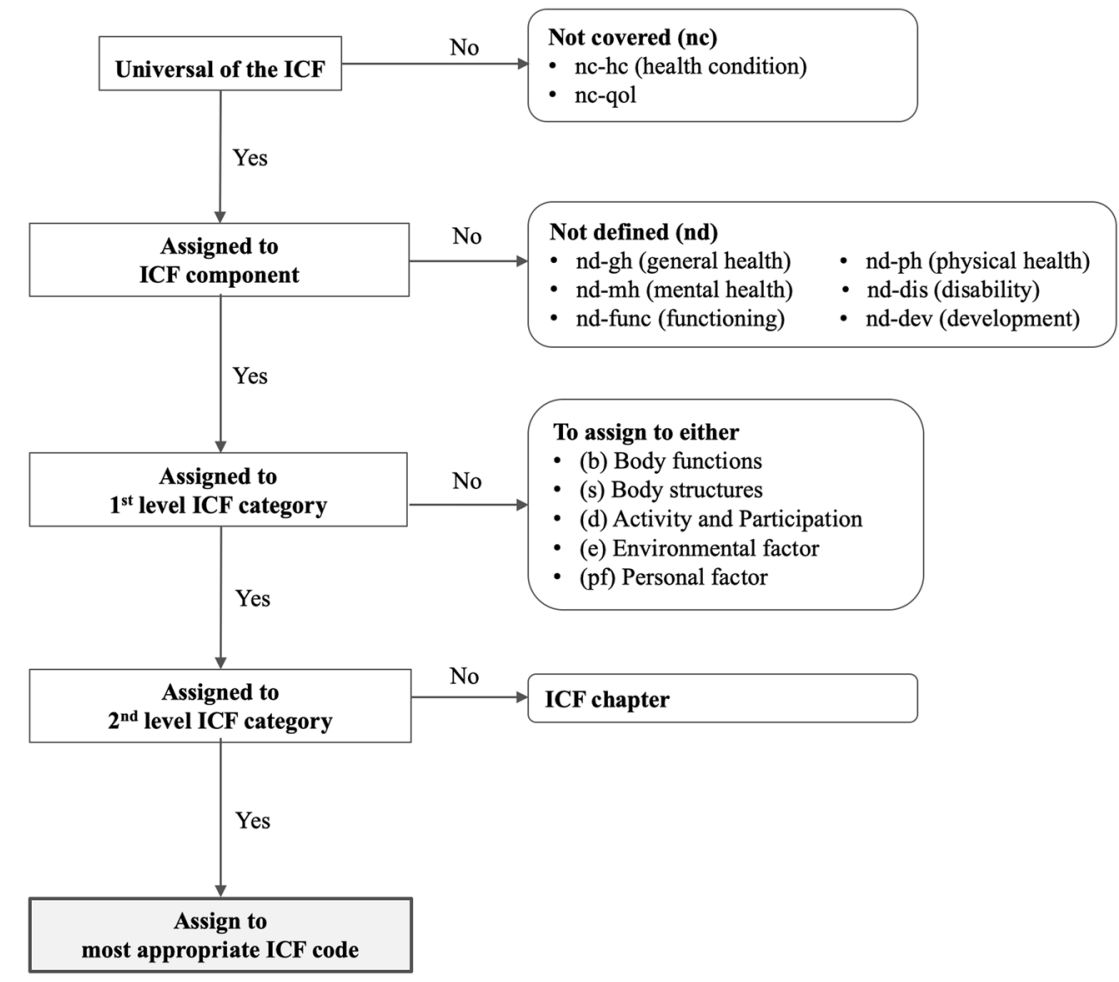

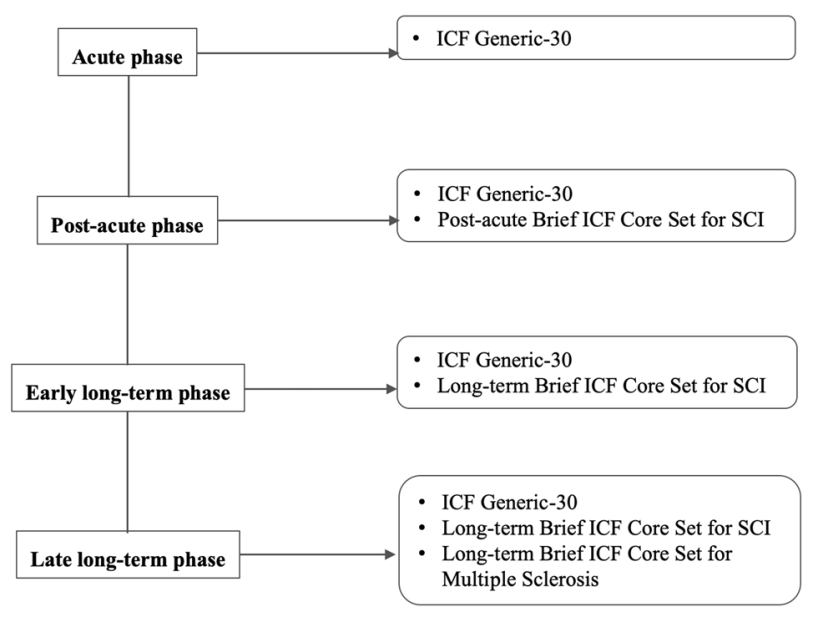

Fig. 3 Selection of the ICF sets based on ICF framework across the continuum of care in SCI rehabilitation (no ICF Core Set for the acute phase of SCI has been provided, no ICF Core Set for the acute and post-acute phases of multiple sclerosis have been provided.). ICF International Classification of Functioning, Disability and Health, SCI spinal cord injury.

The CATs identified in this study are listed in Table 4 . All CATs were administered by a medical doctor. The time points of data collection varied across the cases as shown in Table 4.

The number of the ICF categories identified at the second level when linking the meaningful concepts of PIs to the ICF is shown in Table 5. As shown in Tables 4 and 6, the CATs used in the acute and late long-term phases revealed low correspondence to the selected ICF sets $(4.8 \%$ and $11.3 \%$, respectively), while higher correspondence was found in the post-acute and early long-term phases. However, when adding the findings of PIs, the coverage of the ICF sets increased up to $50 \%$, most notably for the acute and late long-term phases.

Table 6 displays the percentages of how many categories of the ICF sets were covered by the CATs with and without ICF categories identified from PIs across the continuum of care. In the comparison of the CATs and the ICF sets (ICF G-30 and ICF Core Set for SCI in the early post-acute context for the acute and post-acute setting, as well as ICF G-30 and ICF Core Set for SCI in the long-term context for the early and late long-term setting), the categories of the ICF sets most covered by the CATs in all phases were in the component of body functions. The coverage was low particularly in acute and late long-term phase. The ICF components of activities and participation were hardly covered in the late long-term phase, and not at all in the acute phase. Furthermore, none of the CATs used in the acute and late long-term phases address environmental factors. When considering the ICF categories from the PIs with the ICF sets, the coverage increased markedly.

Appendix 2 presents an example of one case in the postacute phase (case 2), showing the results of the comparison between the CATs and the ICF sets with PIs. The CATs covered $<50 \%$ of the categories in the ICF sets. Some functioning categories described in the ICF sets were not covered by any CATs (e.g., b134 sleep functions and d230 
Table 3 Patients' characteristics.

\begin{tabular}{|c|c|c|c|c|c|c|}
\hline \multirow{2}{*}{$\begin{array}{l}\text { Case profiles } \\
\text { Time points }\end{array}$} & \multirow{2}{*}{$\begin{array}{l}\text { Case } 1 \\
\mathrm{~T}_{2}\end{array}$} & \multirow{2}{*}{$\begin{array}{l}\text { Case } 2 \\
\mathrm{~T}_{2}\end{array}$} & \multicolumn{2}{|l|}{ Case 3} & \multicolumn{2}{|l|}{ Case 4} \\
\hline & & & $\mathrm{T}_{1}$ & $\mathrm{~T}_{2}$ & $\mathrm{~T}_{1}$ & $\mathrm{~T}_{2}$ \\
\hline Age (years) & 26 & 33 & 56 & 58 & 43 & 46 \\
\hline Gender & Male & Male & \multicolumn{2}{|l|}{ Male } & \multicolumn{2}{|l|}{ Female } \\
\hline Education & High school (level 6) & $\begin{array}{l}\text { High school } \\
\text { (level 3) }\end{array}$ & \multicolumn{2}{|c|}{ High school (level 3) } & \multicolumn{2}{|c|}{ High school (level 3) } \\
\hline Lesion level & $\mathrm{C} 4$ & $\mathrm{~T} 8$ & \multicolumn{2}{|l|}{$\mathrm{C} 4$} & \multicolumn{2}{|l|}{ T10 } \\
\hline AIS & B & A & \multicolumn{2}{|l|}{$\mathrm{C}$} & \multicolumn{2}{|l|}{$\mathrm{D}$} \\
\hline Etiology & Traumatic SCI (road traffic injury) & $\begin{array}{l}\text { Traumatic SCI } \\
\text { (road traffic injury) }\end{array}$ & \multicolumn{2}{|c|}{$\begin{array}{l}\text { Traumatic SCI (road traffic } \\
\text { injury) }\end{array}$} & \multicolumn{2}{|c|}{$\begin{array}{l}\text { Nontraumatic SCI (multiple } \\
\text { sclerosis; MS) }\end{array}$} \\
\hline Post onset & Admitted on injury day & 11 months & 8 months & 2.5 years & $\begin{array}{l}18 \text { years }(17 \text { th } \\
\text { attack) }\end{array}$ & 21 years \\
\hline Phase of care & Acute & Post-acute & Post-acute & $\begin{array}{l}\text { Early long- } \\
\text { term }\end{array}$ & Late long-term & Late long-term \\
\hline Department & Inpatient, orthopedic & $\begin{array}{l}\text { Inpatient, } \\
\text { rehabilitation }\end{array}$ & \multicolumn{2}{|c|}{ Inpatient, rehabilitation } & $\begin{array}{l}\text { Inpatient, } \\
\text { rehabilitation }\end{array}$ & $\begin{array}{l}\text { MS outpatient } \\
\text { clinic, neurology }\end{array}$ \\
\hline $\begin{array}{l}\text { Length of hospital } \\
\text { stay (days) }\end{array}$ & $\begin{array}{l}45 \text { first admitted at orthopedic } \\
\text { ward (then transferred to } \\
\text { rehabilitation ward) }\end{array}$ & 18 & 24 & $\begin{array}{l}4 \text { (hospital } \\
\text { relief care) }\end{array}$ & 22 & Every 6 months \\
\hline
\end{tabular}

Phase of care means the duration from the onset of SCI to the data collecting date: acute $(<1$ month), post-acute ( 1 month to 1 year), early longterm 1-10 years, late long-term >10 years; length of hospital stay refers to the average number of days that patients spend in hospital from admission to discharge; hospital relief care refers to the short-term admission of the patient to the hospital to reduce caregiver burden (usually of a family member) for a brief period of time.

AIS American Spinal Injury Association Impairment Scale, $T_{1}$ time point at the retrospective, $T_{2}$ time point at time of patient interview.

carrying out daily routine). When adding the data from the PIs, the coverage of categories increased considerably.

The description of the rehabilitation service provided in each case was informed by the SPIs and ordered according to the three dimensions of ICSO-R and their corresponding categories. This description provides the context in which rehabilitation in the four case studies took place. The main difference between the rehabilitation services among the cases was related to service delivery (e.g., the aspect of time and the intensity of rehabilitation program). The rehabilitation service descriptions in tabular form are provided in Appendix 3.

\section{Discussion}

Using a case study approach, this study outlines the first efforts toward developing an ICF-based documentation system for describing functioning in real-life clinical routine in Thailand, specifically for SCI rehabilitation. In this study, ICF sets (core sets and ICF G-30) were applied as a reference to identify which aspects of functioning are important to document for persons with SCI engaged in rehabilitation across the continuum of care.

As shown by the results, the coverage of ICF categories differed depending on the phase of the care continuum. For example, according to the PIs (Table 5), all the ICF components seem to be important in the acute phase, while activities and participations were more prominent in the post-acute phase and environmental factors in the long-term phase. The importance of environmental factors increased when transitioning from the early long-term to the late longterm phase. Nevertheless, when looking at the CATs, it becomes obvious that environmental factors were mostly underrepresented across the continuum of care (Table 6). Given the equally crucial role played by environmental factors, along with body functions, and activities and participation, to optimize functioning of persons with disabilities [2, 4, 5, 8], more efforts to examine the impact of environmental factors (e.g., e135 products and technology for employment and e340 personal care providers and personal assistants) in patient's lives throughout all phases of SCI rehabilitation is warranted. Also, other studies examining the long-term rehabilitation phase of persons with SCI highlight the need for environmental considerations when assessing functioning [24, 30-34]. Thus, it is important to ensure that all ICF components are covered at any point of time along the continuum of care, albeit the emphasis may vary, e.g., body functions may be assessed more and environmental factors less comprehensively in the acute phase than in the long-term rehabilitation phase and vice versa. To ensure comparability and continuity of 


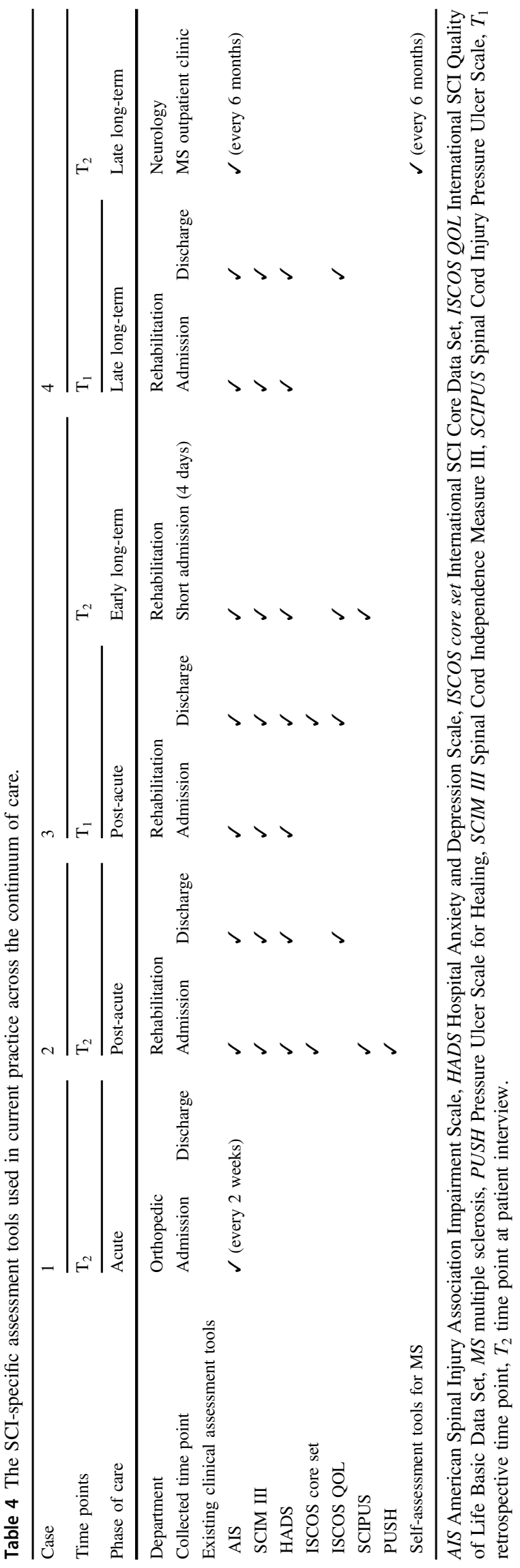

Table 5 Frequency of second-level categories per ICF component identified in the patient interviews.

\begin{tabular}{lllll}
\hline & \multicolumn{4}{l}{ Number of ICF categories per component } \\
\cline { 2 - 5 } Case & 1 & 2 & 3 & 4 \\
ICF components & Acute & $\begin{array}{l}\text { Post- } \\
\text { acute }\end{array}$ & $\begin{array}{l}\text { Early } \\
\text { long term }\end{array}$ & Late long term \\
\hline B & 10 & 12 & 12 & 13 \\
D & 12 & 22 & 16 & 13 \\
E & 11 & 12 & 15 & 18 \\
\hline
\end{tabular}

$B$ body functions, $D$ activities and participations, $E$ environment factors.

information along the continuum of care, core information related to each ICF component collected in the different settings should be comparable.

This study has also some limitations. The results cannot be generalized across rehabilitation settings in Thailand since only four persons with SCI were included in the study. In addition, the CATs used in practice may vary across rehabilitation settings and organization of services, potentially also within countries. The results can also not be generalized across countries since rehabilitation services might may be organized differently in different countries. Nevertheless, the presented cases provide a detailed description of different services, including assessment and documentation practices, across the continuum of rehabilitation care. These cases can inform similar examinations of rehabilitation services in other settings and countries. For instance, when looking at the dimensions of ICSO-R, the main differences resulted in the dimension service delivery which might relate to the different goals of rehabilitation at the different stages across the continuum of care.

Another limitation of the study is that we did not comprehensively examine the health professional's perspective. While we conducted PIs to capture the patient's perspective, the health professional's perspective was reflected solely by the health professional's documentation (health record review; we did not interview them). The documentation may not fully reflect all considerations and clinical reasoning by the health professionals.

In conclusion, this study outlines a framework for developing a standardized reporting system for functioning outcomes in rehabilitation of persons with SCI along the continuum of care based on routine clinical practice using the ICF as the reference. Such a reporting system is important to enhance the information flow throughout the continuum of rehabilitation care and to enable comparisons of functioning outcomes within and across institutions. The result in this study points where data collection can be strengthened to ensure the availability of comprehensive and systematically collected functioning information at any point in the rehabilitation process. 
Table 6 Extent ICF categories in the ICF sets were covered by the CATs with and without the additional ICF categories identified in the PIs.

\begin{tabular}{|c|c|c|c|c|c|c|c|}
\hline \multirow[b]{2}{*}{$\begin{array}{l}\text { Phase } \\
\text { of care }\end{array}$} & \multirow[b]{2}{*}{$\begin{array}{l}\text { ICF } \\
\text { components }\end{array}$} & \multicolumn{3}{|c|}{ ICF sets vs. CATs } & \multicolumn{3}{|c|}{ ICF sets vs. CATs + PI } \\
\hline & & $\begin{array}{l}\text { CATs } \\
(n)\end{array}$ & $\begin{array}{l}\text { ICF sets } \\
(n)\end{array}$ & Coverage $(\%)$ & $\begin{array}{l}\text { CATs and } \\
\text { PI }(n)\end{array}$ & $\begin{array}{l}\text { ICF sets } \\
(n)\end{array}$ & Coverage $(\%)$ \\
\hline \multirow[t]{4}{*}{ Acute } & B & 2 & 9 & 22.2 & 6 & 9 & 66.7 \\
\hline & $\mathrm{D}$ & 0 & 21 & 0 & 7 & 21 & 33.3 \\
\hline & $\mathrm{E}$ & 0 & 12 & 0 & 8 & 12 & 66.7 \\
\hline & Total & 2 & 42 & 4.8 & 21 & 42 & 50.0 \\
\hline \multirow[t]{4}{*}{ Post-acute } & B & 9 & 13 & 69.2 & 11 & 13 & 84.6 \\
\hline & $\mathrm{D}$ & 10 & 23 & 43.5 & 21 & 23 & 91.3 \\
\hline & $\mathrm{E}$ & 5 & 13 & 38.5 & 10 & 13 & 76.9 \\
\hline & Total & 24 & 49 & 49.0 & 42 & 49 & 85.7 \\
\hline \multirow{4}{*}{$\begin{array}{l}\text { Early long- } \\
\text { term }\end{array}$} & B & 8 & 12 & 66.7 & 10 & 12 & 83.3 \\
\hline & $\mathrm{D}$ & 9 & 22 & 40.9 & 16 & 22 & 72.7 \\
\hline & $\mathrm{E}$ & 5 & 13 & 38.5 & 10 & 13 & 76.9 \\
\hline & Total & 22 & 47 & 46.8 & 36 & 47 & 76.6 \\
\hline \multirow{4}{*}{$\begin{array}{l}\text { Late long- } \\
\text { term }\end{array}$} & B & 5 & 15 & 33.3 & 12 & 15 & 80.0 \\
\hline & $\mathrm{D}$ & 1 & 24 & 4.2 & 10 & 24 & 41.7 \\
\hline & E & 0 & 14 & 0 & 10 & 14 & 71.4 \\
\hline & Total & 6 & 53 & 11.3 & 32 & 53 & 60.4 \\
\hline
\end{tabular}

CATs clinical assessment tools, PIs Patient interviews, $B$ body functions, $D$ activities and participations, $E$ environment factors.

\section{Data availability}

The materials used in this study are all public domain. Detailed linking sheets can be requested by the authors.

Acknowledgements The authors thank to Roxanne Maritz who supported the linking process.

Author contributions KP contributed to the design of the study, conducted the data collection and analyses of the study, and played an important role in interpreting the results. She drafted the paper and approved the final version. MS designed the work and played a significant role in identifying the relevant materials for analyses and in interpreting the results. She revised earlier versions of the paper and approved the final version. AK played an important role in recruiting participants for this study and identifying relevant materials and provided valuable feedback in interpreting the results. She revised earlier versions of the paper and approved the final version. BP designed the work, contributed to the identification of the relevant materials, supervised the analyses and interpretation of the results, as well as the drafting of the paper. She revised the paper and approved the final version. All authors agreed to be accountable for all aspects of the work in ensuring that questions related to the accuracy or integrity of any part of the work are appropriately investigated and resolved.

\section{Compliance with ethical standards}

Conflict of interest The authors declare that they have no conflict of interest.

Ethical approval Ethical approval was obtained from Ethical Committee of Faculty of Medicine, Chiang Mai University.
Informed consent All participants signed informed consent before participating.

Publisher's note Springer Nature remains neutral with regard to jurisdictional claims in published maps and institutional affiliations.

\section{References}

1. Stucki G, Bickenbach J, Gutenbrunner C, Melvin J. Rehabilitation: the health strategy of the 21 st century. J Rehabil Med. 2018;50:309-16.

2. World Health Organization. Rehabilitation: key for health in the 21st century. In: Rehabilitation 2030: a call for action. Geneva: WHO; 2017. http://www.who.int/disabilities/care/rehab-2030/en/. Accessed 12 Aug 2018.

3. Stucki G. Olle Höök Lectureship 2015: the World Health Organization's paradigm shift and implementation of the International Classification of Functioning, Disability and Health in rehabilitation. J Rehabil Med. 2016;48:486-93.

4. World Health Organization. Health information systems and rehabilitation. In: Rehabilitation 2030: a call for action. Geneva: WHO; 2017.

5. Stucki G, Bickenbach J. Functioning: the third health indicator in the health system and the key indicator for rehabilitation. Eur $\mathbf{J}$ Phys Rehabil Med. 2017;53:134-8.

6. Stucki G, Bickenbach J, Melvin J. Strengthening rehabilitation in health systems worldwide by integrating information on functioning in National Health Information Systems. Am J Phys Med Rehabil. 2017;96:677-81.

7. World Health Organization. The International Classification of Functioning, Disability and Health. Geneva: WHO; 2001.

8. Stucki G, Bickenbach J. Functioning information in the learning health system. Eur J Phys Rehabil Med. 2017;53:139-43. 
9. Prodinger B, Ballert CS, Cieza A, SwiSCI Study Group. Setting up a cohort study of functioning: from classification to measurement. J Rehabil Med. 2016;48:131-40.

10. Prodinger B, Scheel-Sailer A, Escorpizo R, Stucki G, UEMS PRM ICF Workshop Moderators and Rapporteurs. European initiative for the application of the International Classification of Functioning, Disability and Health: development of Clinical Assessment Schedules for specified rehabilitation services. Eur J Phys Rehabil Med. 2017;53:319-32.

11. Chiodo AE, Scelza WM, Kirshblum SC, Wuermser LA, Ho CH, Priebe MM. Spinal cord injury medicine. 5. Long-term medical issues and health maintenance. Arch Phys Med Rehabil. 2007;88 (3 Suppl 1):S76-83.

12. McKinley WO, Jackson AB, Cardenas DD, DeVivo MJ. Longterm medical complications after traumatic spinal cord injury: a regional model systems analysis. Arch Phys Med Rehabil. 1999;80:1402-10.

13. Sezer N, Akkuş S, Uğurlu FG. Chronic complications of spinal cord injury. World J Orthop. 2015;6:24-33.

14. Sipski ML, Richards JS. Spinal cord injury rehabilitation: state of the science. Am J Phys Med Rehabil. 2006;85:310-42.

15. Nas K, Yazmalar L, Şah V, Aydın A, Öneş K. Rehabilitation of spinal cord injuries. World J Orthop. 2015;6:8-16.

16. Pajareya K. Traumatic spinal cord injuries in Thailand: an epidemiologic study in Siriraj Hospital, 1989-94. Spinal Cord. 1996;34:608-10.

17. Kuptniratsaikul V. Epidemiology of spinal cord injuries: a study in the Spinal Unit, Siriraj Hospital, Thailand, 1997-2000. J Med Assoc Thai. 2003;86:1116-21.

18. Kovindha A. People with spinal cord injury in Thailand. Am J Phys Med Rehabil. 2017;96 2 Suppl 1:S120-3.

19. Wierdsma A, Mulder C, de Vries S, Sytema S. Reconstructing continuity of care in mental health services: a multilevel conceptual framework. J Health Serv Res Policy. 2009;14:52-7.

20. Prodinger B, Cieza A, Oberhauser C, Bickenbach J, Üstün TB, Chatterji $\mathrm{S}$, et al. Toward the International Classification of Functioning, Disability and Health (ICF) rehabilitation set: a minimal generic set of domains for rehabilitation as a health strategy. Arch Phys Med Rehabil. 2016;97:875-84.

21. Avellanet M, Selb M, Stucki G, Cieza A. Utility of using the ICF Core Sets in clinical practice. Rehabilón. 2015;49:197-201.

22. Crowe S, Cresswell K, Robertson A, Huby G, Avery A, Sheikh A. The case study approach. BMC Med Res Methodol. 2011;11:100.

23. Kirchberger I, Cieza A, Biering-Sørensen F, Baumberger M, Charlifue S, Post MW, et al. ICF Core Sets for individuals with spinal cord injury in the early post-acute context. Spinal Cord. 2010;48:297-304.

24. Post MW, Kirchberger I, Scheuringer M, Wollaars MM, Geyh S. Outcome parameters in spinal cord injury research: a systematic review using the International Classification of Functioning, Disability and Health (ICF) as a reference. Spinal Cord. 2010;48:522-8.

25. Ackerman P, Morrison SA, McDowell S, Vazquez L. Using the Spinal Cord Independence Measure III to measure functional recovery in a post-acute spinal cord injury program. Spinal Cord. 2010;48:380-7.

26. Müller M, Strobl R, Grill E. Goals of patients with rehabilitation needs in acute hospitals: goal achivement is an indicator for improved functioning. J Rehabil Med. 2011;43:145-50.

27. Gutenbrunner C, Bickenbach J, Kiekens C, Meyer T, Skempes D, Nugraha B, et al. ISPRM discussion paper: proposing dimensions for an International Classification System for Service Organization in Health-related Rehabilitation. J Rehabil Med. 2015;47:809-15.

28. Cieza A, Fayed N, Bickenbach J, Prodinger B. Refinements of the ICF Linking Rules to strengthen their potential for establishing comparability of health information. Disabil Rehabil. 2019;41:574-83.

29. Cieza A, Kirchberger I, Biering-Sørensen F, Baumberger M, Charlifue S, Post MW, et al. ICF Core Sets for individuals with spinal cord injury in the long-term context. Spinal Cord. 2010;48:305-12.

30. Kirchberger I, Biering-Sørensen F, Charlifue S, Baumberger M, Campbell R, Kovindha A, et al. Identification of the most common problems in functioning of individuals with spinal cord injury using the International Classification of Functioning, Disability and Health. Spinal Cord. 2010;48:221-9.

31. Whiteneck G, Meade MA, Dijkers M, Tate DG, Bushnik T, Forchheimer MB. Environmental factors and their role in participation and life satisfaction after spinal cord injury. Arch Phys Med Rehabil. 2004;85:1793-803.

32. Pollack SF, Zuger RR, Walsh J. Moving out Services for Education and Support (MOSES): a model program for individuals with spinal cord injury. SCI Nurs. 1992;9:79-82.

33. Lysack C, Komanecky M, Kabel A, Cross K, Neufeld S. Environmental factors and their role in community integration after spinal cord injury. Can J Occup Ther. 2007;74:243-54.

34. Cao Y, Walker EA, Krause JS. Environmental barriers and subjective health among people with chronic spinal cord injury: a cohort study. J Spinal Cord Med. 2015;38:526-31. 